\title{
Research
}

\section{Evaluation of primary care 6- to 8-week hip check for diagnosis of developmental dysplasia of the hip:}

a 15-year observational cohort study

\begin{abstract}
Background

The current 6- to 8-week Newborn and Infant Physical Examination (NIPE) clinical assessment is a current standard hip-screening test in the community (England) to detect developmental dysplasia of the hip (DDH).
\end{abstract}

Aim

To assess the value of the primary care 6 - to 8 -week clinical hip examination for the diagnosis of $\mathrm{DDH}$

\section{Design and setting}

A single-centre 15-year observational cohort study at a district general hospital between 1 January 1996 and 31 December 2010

\section{Method}

Those referred by the GP or community practitioner with suspected instability or abnormality of the hip joint (DDH), were clinically and sonographically examined in a specialist hip-screening clinic. Modified Graf Type III and IV and radiological irreducible hip dislocation were considered to be "pathological' hips. Screening failures were defined as those who had not been identified by this primary care screening assessment (but had irreducible hip dislocation). Secondary univariate and multivariable analyses were performed to determine which clinical findings are predictive of instability.

\section{Results}

Over the study period, there were 70071 infants who underwent the 6- to 8-week clinical hip assessment. In the specialist hip-screening clinic, six (from the 170 referred) were diagnosed with pathological DDH. The sensitivity, specificity, positive predictive value, and negative predictive value for the 6 - to 8 -week clinical hip assessment were $16.7 \%, 99.8 \%, 3.5 \%$, and $100.0 \%$, respectively. A multivariable model showed a positive Ortolani manoeuvre to be the sole independent predictor of instability at 6 to 8 weeks.

\section{Conclusion}

This 15-year study highlights the limitations of a hip check at 6 to 8 weeks. These findings support the reassessment of the national guidelines for this aspect of the NIPE DDH screening programme.

\section{Keywords}

clinical examination; cohort studies; hip dysplasia primary healthcare; screening.

\section{INTRODUCTION}

Developmental dysplasia of the hip (DDH) is a common cause of musculoskeletal childhood disability, with a quoted incidence between 1.4 in 1000 and 20 in 1000 live births. ${ }^{1-3}$ The 1969 and 1986 guidelines of the Standing Medical Advisory Committee for the Department of Health ${ }^{4}$ recommended clinical primary care assessment of the hips at 6 weeks of age. Until recently, little evidence has been published on the efficacy of this hip joint assessment.

The Newborn and Infant Physical Examination (NIPE) handbook ${ }^{5,6}$ documents the current guidance (6- to 8-week infant hip joint physical examination in England). This second clinical hip-screening examination occurs within a period of uncertainty, during which the signs of instability (Barlow and Ortolani manoeuvres) are resolving, but the development of limitation of hip abduction has not yet developed.?

There is controversy regarding the true value of the current screening programme for $\mathrm{DDH}$ in the UK. The current NIPE programme does not meet most of the accepted criteria for successful screening. Although the value of the newborn hipscreening programme has been extensively investigated with inconclusive results, ${ }^{8-11}$ the 6- to 8-week infant physical examination hip-screening assessment has never been formally audited in England by the NIPE. This study was undertaken to assess the

R Davies, MMedSci, FRCS (T\&0), consultant orthopaedic surgeon, Department of Trauma and Orthopaedics, Royal Manchester Infirmary, Manchester. C Talbot. FRCS (T\&O), consultant paediatric orthopaedic surgeon, Department of Paediatric Trauma and Orthopaedics, Alder Hey Childrens NHS Foundation Trust, Liverpool. R Paton, FRCS (Orth), PhD, consultant orthopaedic surgeon, Department of Trauma and Orthopaedics, Royal Blackburn Hospital, Blackburn; honorary professor, School of Medicine, University Central Lancashire, Preston. effectiveness of the primary care 6- to 8-week clinical hip assessment.

\section{METHOD}

From 1 January 1996 to 31 December 2010, a prospective cohort study, at a single District General Hospital in the UK, was undertaken on a birth cohort of 75432 . Data collection occurred using a standard proforma, with electronic data storage using Microsoft Excel. The study had approval from the Ethical Committee and the Research and Development Committee of East Lancashire Hospitals NHS Trust.

All patients who were referred from general or community practitioners with a suspected clinically unstable hip or a clinical hip abnormality associated with $\mathrm{DDH}$, at the first clinical primary care hip assessment, were included in the study. There were separate pathways of referral from the Paediatric department for newborn cases of instability and at risk' cases (Breech presentation and strong family history of DDH). These cases were not included in this analysis. Patients with syndromal or neurological diseases associated with hip dysplasia and instability were excluded.

Due to the rarity of positive pathological $\mathrm{DDH}$ (in the 6- to 8-week assessment) identified in a previous 10 -year study ${ }^{12}$ $(n=2)$, the study was extended to 15 years.

\section{Address for correspondence}

Christopher Talbot, Paediatric Trauma and Orthopaedics, Alder Hey Childrens NHS

Foundation Trust, East Preston Road, Liverpool L14 5AB, UK.

Email: Christopher.talbotdalderhey.nhs.uk Submitted: 13 April 2019; Editor's response: 30 July 2019; final acceptance: 27 August 2019. CBritish Journal of General Practice

This is the full-length article (published online 25 Feb 2020) of an abridged version published in print. Cite this version as: $\mathbf{B r} \mathbf{J}$ Gen Pract 2020; DOI: https://doi.org/10.3399/bjgp20X708269 


\section{Table 1. Contingency table for performance of the 6- to 8-week screening test for DDH}

\begin{tabular}{lcc} 
& $\begin{array}{c}\text { DDH } \\
\text { present }\end{array}$ & $\begin{array}{c}\text { DDH not } \\
\text { present }\end{array}$ \\
\hline $\begin{array}{l}\text { Screened positive at } \\
\text { 6-8 weeks check }\end{array}$ & 6 & 164 \\
\hline $\begin{array}{l}\text { Screened negative at } \\
\text { 6-8 weeks check }\end{array}$ & 30 & 69871 \\
\hline
\end{tabular}

$D D H=$ developmental dysplasia of the hip.

\section{How this fits in}

The incidence of late-diagnosed developmental dysplasia of the hip (DDH) has not been reduced from that reported 35 years ago, prior to the introduction of the national selective screening programme for $\mathrm{DDH}$. The 6- to 8-week Newborn and Infant Physical Examination clinical assessment is one arm of this assessment. If the 6- to 8-week clinical hip assessment continues to be a part of this screening method, the major referral criteria that should be considered are a positive Ortolani or Barlow manoeuvre and unilateral limited hip abduction, as the findings of this study suggest.

\section{Clinical assessment and data collection.}

In all cases, all the hip joints were clinically and sonographically assessed in a unique specialist 'one stop' hip clinic (clinical examination and ultrasound imaging undertaken by the senior author). Clinical examination included Barlow ${ }^{13}$ and Ortolani $i^{14}$ manoeuvres and an assessment for limited hip abduction. Each patient had an ultrasound examination of both hip joints, and this was performed with the neonate on their side (coronal flexion view) and scanned in real time using modified Harcke dynamic and modified Graf static methods. 15,16

Individuals with modified Graf Type III and IV hips were classified as "pathological (as advocated by Rosendahl)17,18 and were treated in a Pavlik harness. Patients with abnormal $\alpha$-angles, Graf Type II l $\alpha$-angles $<60$ degrees and >43 degrees, but otherwise stable hips, no subluxation, or dislocation on dynamic scan) received a follow-up scan until considered normal or until the hip progressed to 'pathological' or irreducible dislocation. If the hip progressed into a pathological type, it was included in the analysis as a true positive case.

The data were collected prospectively, and included patient demographics, reasons for referral, risk factors for DDH (breech and family history), and abnormal clinical signs (Barlow or Ortolani manoeuvre positive, asymmetrical skin creases, limited hip abduction [unilateral or bilateral], lower limb length discrepancy, and 'clicky' hips). Screening failures (false negatives) were defined as patients who presented with pathological hip joints (sonographic or radiographic) after 16 weeks of age. This data was analysed retrospectively. Data were taken from a minimum 24-month period following completion of the study to ensure capture of late presenting cases, and to ensure an accurate false negative rate. To account for variations in the timing of newborn examinations and delays between referral and clinic review, patients seen between 4 and 16 weeks of age were included. This allowed for early GP referral and time slippage in referrals to the specialist hip clinic due to administrative reasons.

\section{Statistical analysis}

Data analysis used IBM SPSS Statistics (version 22). Univariate analysis of dichotomous variables was undertaken using Fisher's Exact tests. Odds ratios and their $95 \%$ confidence intervals for each parameter were calculated for each variable. A multivariable logistic regression model was then obtained. Parameters with $P<0.1$ in the univariate analysis were entered into a backward stepwise elimination model with likelihood-ratio testing, stopping when all $P$-values were $>0.05$

\section{RESULTS}

Over the study period there were 74532 live births on record from census data. Of these, 4461 individuals were identified as part of the newborn and at-risk screening programme. The remaining 70071 were considered to have undergone the primary care 6- to 8-week hip examination (Table 1).

In 15 years of the study, there were 170 patients identified and referred from the 6- to 8-week 'hip check'. Of these, 164 were Graf Type I, and none were Type II. 'Pathological' hips were diagnosed in six individuals. There were no bilateral dislocations. The most common reason for referral to the 'one stop' hip clinic was 'clicky hip', followed by limited hip abduction (Table 2). Of the six 'pathological' hips diagnosed, four were Graf Type IV, and two were irreducible dislocations (Table 3). Two cases were successfully treated with a Pavlik harness. Three patients required closed reduction with a hip spica, and one required anterolateral open reduction and femoral derotation osteotomy. One of the patients requiring closed reduction required further surgery (pelvic osteotomy) at the age of 27 months. Overall, there were 30 late presenting cases of irreducible hip dislocation identified (born within the 15-year study period). Their ages at presentation and treatments are summarised in Table 4. All late presenting patients were referred from, and born within, the catchment for this study. Administrative errors did not account for late presenting cases. All 
Table 3. Patients with 'pathological' hip diagnosis from 6- to 8-week check

\begin{tabular}{|c|c|c|c|c|c|c|c|}
\hline & Sex & $\begin{array}{l}\text { Age at examination, } \\
\text { weeks }\end{array}$ & Reason for referral & Hip classification & Initial treatment & $\begin{array}{l}\text { Successful } \\
\text { Pavlik }\end{array}$ & $\begin{array}{l}\text { Additional } \\
\text { treatment }\end{array}$ \\
\hline Patient 1 & Female & 10 & Ortolani positive & Graf IV & Pavlik Harness & No & $\begin{array}{l}\text { Closed reduction } \\
\text { and spica }\end{array}$ \\
\hline Patient 2 & Female & 11 & $\begin{array}{l}\text { Ortolani positive / } \\
\text { unstable }\end{array}$ & Irreducible & Pavlik Harness & No & $\begin{array}{l}\text { Medial open } \\
\text { reduction }^{\mathrm{a}}\end{array}$ \\
\hline Patient 3 & Female & 12 & Unstable & Graf IV & Pavlik Harness & Yes & \\
\hline Patient 4 & Female & 13 & Limited hip abduction & Graf IV & Pavlik Harness & Yes & \\
\hline Patient 5 & Female & 13 & $\begin{array}{l}\text { Ortolani and Barlow } \\
\text { positive }\end{array}$ & Irreducible & Pavlik Harness & No & $\begin{array}{l}\text { Closed reduction } \\
\text { and spica }\end{array}$ \\
\hline Patient 6 & Male & 14 & Risk factor CTCV & Graf IV & $\begin{array}{l}\text { Closed reduction } \\
\text { and spica }\end{array}$ & $\begin{array}{l}\text { Not } \\
\text { attempted }\end{array}$ & Pelvic osteotomy \\
\hline
\end{tabular}

${ }^{a}$ Needed further anterior open reduction and femoral osteotomy. CTCV = congenital talipes calcaneovalgus.

Table 4. Ages and treatments for late dislocations

\begin{tabular}{|c|c|c|c|c|c|}
\hline Case number & $\begin{array}{l}\text { Age at presentation, } \\
\text { weeks }\end{array}$ & $\begin{array}{l}\text { Closed } \\
\text { reduction }\end{array}$ & $\begin{array}{c}\text { Open } \\
\text { reduction }\end{array}$ & $\begin{array}{c}\text { Femoral } \\
\text { osteotomy }\end{array}$ & $\begin{array}{c}\text { Pelvic } \\
\text { osteotomy }\end{array}$ \\
\hline 1 & 18 & $Y_{e s}{ }^{a}$ & Yes & - & Yes \\
\hline 2 & 18 & Yes & - & - & - \\
\hline 3 & 19 & - & Yes & - & - \\
\hline 4 & 29 & - & Yes & - & - \\
\hline 5 & 32 & - & Yes & - & - \\
\hline 6 & 36 & - & Yes & - & - \\
\hline 7 & 39 & Yes & - & - & - \\
\hline 8 & 48 & - & Yes & - & Yes \\
\hline 9 & 56 & Yes $^{a}$ & - & - & Yes \\
\hline 10 & 65 & - & Yes & - & Yes \\
\hline 11 & 65 & - & Yes & Yes & Yes \\
\hline 12 & 68 & - & Yes & Yes & Yes \\
\hline 13 & 70 & - & Yes & - & Yes \\
\hline 14 & 72 & - & Yes & Yes & Yes \\
\hline 15 & 72 & - & Yes & - & Yes \\
\hline 16 & 72 & - & Yes & - & Yes \\
\hline 17 & 73 & - & Yes & - & - \\
\hline 18 & 78 & - & Yes & - & Yes \\
\hline 19 & 78 & Yes & - & - & - \\
\hline 20 & 78 & - & Yes & Yes & Yes \\
\hline 21 & 78 & - & Yes & Yes & Yes \\
\hline 22 & 82 & - & Yes & Yes & Yes \\
\hline 23 & 82 & - & Yes & Yes & Yes \\
\hline 24 & 91 & - & Yes $^{b}$ & Yes & - \\
\hline 25 & 104 & - & - & - & Yes \\
\hline 26 & 117 & - & - & - & Yes \\
\hline 27 & 117 & - & Yes & - & Yes \\
\hline 28 & 200 & - & - & - & Yes \\
\hline 29 & 242 & - & Yes & Yes & Yes \\
\hline 30 & 260 & - & Yes & Yes & Yes \\
\hline
\end{tabular}

late presenting hips were referred by the patients GP or paediatrician.

The sensitivity, specificity, positive predictivevalue (PPV), and negative predictive value (NPV) for the 6- to 8-week check were $16.7 \%$ (95\% confidence interval $[\mathrm{Cl}]=6.37$ to 32.8$), 99.8 \% \quad(95 \% \quad \mathrm{Cl}=99.7$ to 99.8$)$, $3.5 \%(95 \% \mathrm{Cl}=1.71$ to 7.16$)$, and $100.0 \%$ (95\% $\mathrm{Cl}=99.9$ to 100.0$)$, respectively.

Of the 5 patients referred with a positive Ortolani hip examination, four (80\%) were confirmed as clinically Ortolani positive in the 'one-stop' hip clinic and had a confirmed sonographic 'pathological' hip. Univariate analysis revealed positive Ortolani manoeuvres and patients referred as 'unstable' to be significant predictors of 'pathological' hips. Following data entry into a multivariable model, a positive Ortolani manoeuvre was found to be the only independent predictor of instability $(P<0.001)$ (Table 5).

In this series, two cases would have been missed if the Ortolani and/or unstable clinical test for referral alone had been used by the GP as the most important clinical sign. One case presented later, at 13 weeks of age, with unilateral limited hip abduction and a clinically stable joint, and the other was secondary to the risk factor of congenital talipes calcaneovalgus.

\section{DISCUSSION}

\section{Summary}

This study demonstrates that the sensitivity $(16.7 \%)$ and PPV (3.5\%) of the screening test for DDH at 6- to 8-weeks is low, resulting in screening failures (false negative cases), and possibly providing false reassurance to parents. Clinical signs of instability (Ortolani and Barlow manoeuvres) and presence of unilateral limitation of hip abduction 


\section{Table 5. Univariate analysis, with odds ratio for 'pathological' developmental dysplasia of the hip (DDH)}

\begin{tabular}{lcccc} 
Variable & Normal & Pathological & Univariate OR (95\% Cl)a & $\boldsymbol{P}_{\text {-value }}$ \\
\hline Age, weeks & - & - & 1.002 (0.72 to 1.39) & 0.992 \\
\hline Referred 'Ortolani / Barlow positive' & 1 & 4 & 326 (24 to 4377) & $<0.001$ \\
\hline Referred 'unstable' & 7 & 2 & 11.2 (1.7 to 72) & 0.03 \\
\hline Referred 'clicky' hip & 73 & 0 & 0 & 1.00 \\
\hline Limited hip abduction & 38 & 1 & 0.66 (0.08 to 5.85) & 1.00 \\
\hline Family history of DDH & 8 & 0 & 1 & 1.00 \\
\hline Breech & $10^{\text {b }}$ & 0 & $1.44(0.16$ to 12.96) & 0.55 \\
\hline Other risk factor & 20 & 1 c & 1 & 1.00 \\
\hline Leg length inequality & 6 & 0 & 1 & 1.00 \\
\hline Caesarean delivery & 4 & 0 & 0 & 1.00
\end{tabular}

${ }^{a}$ Confidence intervals are not shown for all variables. ${ }^{b}$ Eight also had another risk factor other than family

history and one also referred with clicky hip. ${ }^{\circ}$ Congenital talipes calcaneovalgus. $\mathrm{Cl}=$ confidence interval. $\mathrm{DDH}=$

developmental dysplasia of the hip. OR = odds ratio. clinical screening and risk factors were asked. To mitigate any potential issues with administrative delays, the inclusion window was extended to 16 weeks. Data were analysed on an 'intention-to-screen' basis, so if infants did not have their 6- to 8-week check, or it occurred late, it was still regarded as a screening failure.

With respect to bias, there is the potential for information bias in terms of the reading and interpretation of ultrasound results. Random measurement errors arising from imprecision of the ultrasound and user were kept to a minimum by ensuring the senior author, experienced in ultrasonography and diagnosis of DDH, undertook all ultrasounds and interpreted all results.

\section{Comparison with existing literature}

The advantages and disadvantages of universal and selective screening for $\mathrm{DDH}$ are evidenced in the literature. ${ }^{18,20-22}$ Despite the national selective screening programme in England, Broadhurst et a l $^{23}$ have shown the incidence of late presenting DDH to have remained similar over a 26-year period. The study examined all children aged between 1 year and 8 years from 1 January 1990 to 1 January 2016 who had a new first diagnostic code for DDH. There has been little in the way of work undertaken to assess the hip check as part of the 6-to 8-week check in primary care.

Reidy et al ${ }^{19}$ assessed the sensitivity, specificity, and PPV of the examination at 6- to 8-weeks as part of the DDH surveillance system in a region in Scotland. This was a 5-year study period with 23112 live births, confirming 141 cases of DDH. The sensitivity, specificity, and PPV of the examination were found to be $19.4 \%, 98 \%$, and $1.5 \%$, respectively. This current study supports this work and adds to the evidence regarding the reliability of this 'safety net' check for DDH.

Groarke et $a l^{24}$ in a retrospective multicenter review of 174 patients in Ireland, reported that the clinical examination by GPs did not reliably detect radiographically defined DDH. Asymmetrical skin folds, hip click, limb shortening, and limited abduction all had a low sensitivity. Following a logistic regression analysis, no clinical signs, prompting a referral from the GP, were found to be a significant indicator of an abnormal acetabular index. This suggests that the failure to identify many cases of pathological DDH is related to a lack of clinical signs, or the presence of subtle clinical signs that are difficult to diagnose.

In the present study, the clinical signs of instability (Ortolani and Barlow manoeuvres) 
and presence of unilateral limitation of hip abduction were the important signs in the detection of pathological DDH. This study highlights the importance of the Ortolani manoeuvre in the detection of DDH at the 6- to 8-week clinical hip assessment; however, the Ortolani manoeuvre was never positive after 13 weeks in the six patients with 'pathological' hips identified, questioning the use of this test if the 6- to 8-week assessment is delayed. Furthermore, the traditional problem with clinical hip-screening tests is that the Ortolani manoeuvre is only $60 \%$ sensitive in the newborn assessment. ${ }^{25,26}$ Barlow and Ortolani manoeuvres failed to identify $66.7 \%$ of those hip joints that subsequently required surgical intervention. ${ }^{27}$

The Ortolani and Barlow manoeuvres may spontaneously resolve in $70 \%-90 \%$ of cases within 2 to 4 weeks postnatally. ${ }^{13}$ This, coupled with the development of unilateral limitation of hip abduction not becoming clinically obvious until approximately 3 months of age, ${ }^{28,29}$ suggests that the timing of the 6- to 8-week clinical assessment may fall between the resolution of clinical hip instability and the development of the unilateral limitation of hip abduction. This raises the concern that the 6- to 8-week time frame is poorly timed, and suboptimal in its aim to identify 'pathological' DDH. This supports a recommendation to alter the timing of this examination or to consider an additional hip check at a later date.30,31

\section{Implications for research and practice}

A recent publication from Scotland ${ }^{32}$ has highlighted substantial reductions in late diagnosis of DDH through the implementation of enhanced $\mathrm{DDH}$ detection services with expert examiners at the newborn assessment. This, coupled with the present study's findings, prompts further research to determine at what point, and by whom, the hip clinical surveillance examination would be most effective in detecting DDH.

It must be emphasised that the results of the present study support the authors view that there needs to be a greater understanding of the limitations of the 6 - to 8-week hip check, in particular, the timing of this check; rather than reflecting the level of experience of clinicians and health professionals who perform the hip check as part of the whole child assessment at this time in the child's development.

The results from the present study, in terms of low sensitivity and PPV of the hip check at the 6- to 8-week assessment, may be due to the suboptimum nature of the test and timing of it. The authors recommend that, if the hip check remains as part of the 6- to 8-week clinical assessment, which is performed in primary care, clinicians must be aware of the limitations of $\mathrm{DDH}$ screening, and that examination for a positive Ortolani or Barlow manoeuvre and unilateral limited hip abduction are clinically important findings.

As such, the authors would advocate that the newborn clinical examination be undertaken by a small group of trained health professionals, and that there is the introduction of a 3- to 4-month clinical hip examination to identify unilateral limited hip abduction. This second proposal may help to identify the current late presenting infants with pathological hips earlier and reduce the risk of corrective osteotomy. This examination could be performed in primary care with appropriately trained healthcare professionals.

Furthermore, the authors recommend that as part of the 6-to 8-week check more emphasis should be placed on the education of parents about the information contained in the 'red book' regarding DDH and clinical features of concern. In conclusion, since 1969, the 6- to 8-week primary care clinical hip assessment for DDH has been regarded as a standard, effective method of detecting early pathological DDH. This 15-year study highlights the significant limitations and complexities of this assessment in the diagnosis of pathological DDH. The authors recommend the introduction of a later specific hip check as part of a change to the national guidelines for this aspect of the NIPE DDH screening guidelines.

\section{Ethics}

This study received both local ethics committee and hospital trust research and development committee approval.

\section{Competing interests}

The authors have declared no competing interests.

\section{Discuss this article}

Contribute and read comments about this article: bjgp.org/letters 


\section{REFERENCES}

1. Committee on Quality Improvement, Subcommittee on Developmental Dysplasia of the Hip. Clinical practice guideline: early detection of developmental dysplasia of the hip. Pediatrics 2000; 105(4): 896-905.

2. Witt C. Detecting developmental dysplasia of the hip. Adv Neonatal Care 2003; 3(2): 65-75.

3. Garvey M, Donoghue VB, Gorman WA, et al. Radiographic screening at four months of infants at risk for congenital hip dislocation. J Bone Joint Surg Br 1992; 74(5): 704-707.

4. Screening for the detection of congenital dislocation of the hip. Arch Dis Child 1986; 61(9): 921-926.

5. Public Health England. Newborn and infant physical examination (NIPE) screening programme handbook. 2019. https://www.gov.uk/government/ publications/newborn-and-infant-physical-examination-programmehandbook/newborn-and-infant-physical-examination-screening-programmehandbook\#examination-of-the-hips (accessed 12 Feb 2020).

6. Public Health England. Our approach to newborn and infant physical examination screening standards. 2018. https://uww.gov.uk/government/ publications/newborn-and-infant-physical-examination-screening-standards/ our-approach-to-newborn-and-infant-physical-examination-screeningstandards (accessed 4 Feb 2020)

7. Artz TD, Lim WN, Wilson PD, et al. Neonatal diagnosis, treatment and related factors of congenital dislocation of the hip. Clin Orthop Relat Res 1975; 110 $112-136$

8. Paton RW. Screening in Developmental Dysplasia of the Hip (DDH). Surgeon 2017; 15(5): 290-296.

9. American Academy of Orthopedic Surgeons. Detection and nonoperative management of pediatric developmental dysplasia of the hip in infants up to six months of age. Evidence-based clinical practice guideline. 2014. https://www. aaos.org/research/guidelines/DDHGuidelineFINAL.pdf (accessed 21 Jan 2020).

10. Shipman SA, Helfand M, Moyer VA, Yawn BP. Screening for development dysplasia of the hip: a systematic literature review for the US Preventive Services Task Force. Pediatrics 2006; 117(3): e557-e576.

11. Shorter D, Hong T, Osborn DA. Cochrane Review: screening programmes for developmental dysplasia of the hip in newborn infants. Evid Based Child Health 2013; 8(1): 11-54.

12. Paton RW. Does selective ultrasound imaging of 'at risk' hip and clinically unstable hips, in developmental dysplasia of the hip (DDH) produce an effective screening programme. PhD Thesis, University of Lancaster, 2011. EThOS ID: uk.bl.ethos.618306.

13. Barlow TG. Early diagnosis and treatment of congenital dislocation of the hip. Proc R Soc Med 1963; 56: 804-806.

14. Ortolani M. A little sign and its relevant importance in the early diagnosis of congenital dislocation of the hip. [In Italian]. La Pediatria 1937; 45: 129-136.

15. Tachdjian MO. Congenital dysplasia of the hip. In: Tachdjian MO. Pediatric Orthopedics. (2nd edn). Philadelphia, PA: WB Saunders Company, 1990.
16. Paton RW, Srinivasan MS, Shah B, Hollis S. Ultrasound screening for hips at risk in developmental dysplasia. Is it worth it? J Bone Joint Surg Br 1999; 81(2): 255-258.

17. Rosendahl K, Toma P. Ultrasound in the diagnosis of developmental dysplasia of the hip in newborns. The European approach. A review of methods, accuracy and clinical validity. Eur Radiol 2007; 17(8): 1960-1967.

18. Rosendahl K, Markestad T, Lie RT. Ultrasound screening for developmental dysplasia of the hip in the neonate: the effect on treatment rate and prevalence of late cases. Pediatrics 1994; 94(1): 47-52.

19. Reidy M, Collins C, MacLean JGB, Campbell D. Examining the effectiveness of examination at 6-8 weeks for developmental dysplasia: testing the safety net. Arch Dis Child 2019; 104(10): 953-955.

20. Ihme N, Altenhofen L, von Kries R, Niethard FU. Hip ultrasound screening in Germany. Results and comparison with other screening procedures. Orthopade 2008; 37(6): 548-549

21. von Kries R, Ihme N, Oberle D, et al. Effect of ultrasound screening on the rate of first operative procedures for developmental hip dysplasia in Germany. Lancet 2003; 362(9399): 1883-1887.

22. Gray A, Elbourne D, Dezateux C, et al. Economic evaluation of ultrasonography in the diagnosis and management of developmental hip dysplasia in the United Kingdom and Ireland. J Bone Joint Surg Am 2005; 87(11): 2472-2479.

23. Broadhurst $C$, Rhodes AML, Harper $P$, et al. What is the incidence of late detection of developmental dysplasia of the hip in England?: A 26-year national study of children diagnosed after the age of one. Bone Joint J 2019; 101-B(3): 281-287.

24. Groarke PJ, McLoughlin L, Whitla L, et al. Retrospective multicenter analysis of the accuracy of clinical examination by community physicians in diagnosing developmental dysplasia of the hip. J Pediatr 2017; 181: 163-166.

25. Jones D. Editorial neonatal detection of developmental dysplasia of the hip (DDH). J Bone Joint Surg Br 1998; 80(6): 943-945.

26. Jones $D$. An assessment of the value of examination of the hip in the newborn J Bone Joint Surg Br 1977; 59(3): 318-322.

27. Robinson R. Effective screening in child health. BMJ 1998; 316(7124): 1-2

28. Choudry Q, Goyal R, Paton RW. Is limitation of hip abduction a useful clinical sign in the diagnosis of developmental dysplasia of the hip? Arch Dis Child 2013; 98(11): 862-866.

29. Jari S, Paton RW Srinivasan MS. Unilateral limitation of abduction of the hip. A valuable clinical sign for DDH? J Bone Joint Surg Br 2002; 84(1): 104-107.

30. Price KR, Dove R, Hunter JB. Current screening recommendations for developmental dysplasia of the hip may lead to an increase in open reduction. Bone Joint J 2013; 95(6): 846-850.

31. Talbot C, Adam J, Paton R. Late presentation of developmental dysplasia of the hip: a 15-year observational study. Bone Joint J 2017; 99-B(9): 1250-1255.

32. McAllister DA, Morling JR, Fischbacher CM, et al. Enhanced detection services for developmental dysplasia of the hip in Scottish children, 1997-2013. Arch Dis Child 2018; 103(11): 1021-1026. 